\title{
T-cell based immunotherapies for Parkinson's disease
}

\author{
Rodrigo Pacheco ${ }^{1,2 *}$ (1) \\ ${ }^{1}$ Laboratorio de Neuroinmunología, Fundación Ciencia \& Vida, Ñuñoa, Santiago 7780272, Chile \\ ${ }^{2}$ Facultad de Medicina y Ciencia, Universidad San Sebastián, Providencia, Santiago 7510156, Chile
}

*Correspondence: Rodrigo Pacheco, Laboratorio de Neuroinmunología, Fundación Ciencia \& Vida, Av. Zañartu 1482, Ñuñoa, Santiago 7780272, Chile.rpacheco@cienciavida.org; rodrigo.pacheco@uss.cl

Academic Editor: Raymond Chuen-Chung Chang, The University of Hong Kong, China

Received: July 21, 2021 Accepted: September 8, 2021 Published: October 29, 2021

Cite this article: Pacheco R. T-cell based immunotherapies for Parkinson's disease. Explor Neuroprot Ther. 2021;1:72-85. https://doi.org/10.37349/ent.2021.00007

\begin{abstract}
Current evidence indicates that neurodegeneration of dopaminergic neurons of the substantia nigra associated to Parkinson's disease is a consequence of a neuroinflammatory process in which microglial cells play a central role. The initial activation of microglial cells is triggered by pathogenic protein inclusions, which are mainly composed by $\alpha$-synuclein. Importantly, these pathogenic forms of $\alpha$-synuclein subsequently induce a T-cell-mediated autoimmune response to dopaminergic neurons. Depending on their functional phenotype, these autoreactive T-cells might shape the functional features of activated microglia. T-cells bearing pro-inflammatory phenotypes such as T-helper (Th)1 or Th17 promote a chronic inflammatory behaviour on microglia, whilst anti-inflammatory T-cells, such as regulatory T-cells (Treg) favour the acquisition of neuroprotective features by microglia. Thus, T-cells play a fundamental role in the development of neuroinflammation and neurodegeneration involved in Parkinson's disease. This review summarizes the evidence indicating that not only CD4+ $\mathrm{T}$-cells, but also CD8 ${ }^{+} \mathrm{T}$-cells play an important role in the physiopathology of Parkinson's disease. Next, this review analyses the different T-cell epitopes derived from the pathogenic forms of $\alpha$-synuclein involved in the autoimmune response associated to Parkinson's disease in animal models and humans. It also summarizes the requirement of specific alleles of major histocompatibility complexes (MHC) class I and class II necessaries for the presentation of CD8 ${ }^{+}$and $\mathrm{CD}^{+}$ T-cell epitopes from the pathogenic forms of $\alpha$-synuclein in both humans and animal models. Finally, this work summarizes and discusses a number of experimental immunotherapies that aim to strengthen the Treg response or to dampen the inflammatory T-cell response as a therapeutic approach in animal models of Parkinson's disease.
\end{abstract}

\section{Keywords}

Parkinson's disease, neuroinflammation, neurodegeneration, $\mathrm{T}$ cells, regulatory $\mathrm{T}$ cells, alpha-synuclein, immunotherapy 


\section{Introduction}

Parkinson's disease is a neurodegenerative disorder that affect mainly the dopaminergic neurons of the nigrostriatal pathway. Since these neurons are involved in the control of voluntary movement, the most characteristic symptom associated to this pathology is a motor impairment, including bradykinesia, postural instability, tremors, and rigidity. This disorder also involves the generation of pathogenic protein inclusions in the brain, which are composed mainly by a pre-synaptic protein called $\alpha$-synuclein ( $\alpha$ Syn) [1]. It has been described that these pathogenic deposits of $\alpha$ Syn are generated by misfolded and post-translational modifications of $\alpha$ Syn induced by oxidative stress and aberrant phosphorylation [2].

Current evidence indicates that neurodegeneration involved in Parkinson's disease is a consequence of a chronic inflammatory process of the nigrostriatal pathway [3]. Importantly, microglial cells are the central players in this neuroinflammatory process. In this regard, it has been described that initial microglial activation is triggered by pathogenic forms of $\alpha$ Syn, which stimulate toll-like receptors (TLRs) on these cells [4, 5]. Afterwards, microglia might acquire a pro-inflammatory behaviour, called M1 microglia, which produces inflammatory mediators and neurotoxic factors such as glutamate, reactive oxygen species (ROS), reactive nitrogen species (RNS) and tumour necrosis factor $\alpha$ (TNF $\alpha$ ), all of which might induce neuronal death directly [6]. On the other hand, microglia might acquire an anti-inflammatory functional phenotype, called M2 microglia, which release anti-inflammatory mediators and neurotrophic factors, such as glial cell-derived neurotrophic factor, brain-derived neurotrophic factor, insulin-like growth factor 1 and others, which dampen inflammation and promote neuronal survival and tissue repair [6]. Thus, the acquisition of a particular functional phenotype by microglia might define the development of neuroinflammation and the consequent neurodegeneration in Parkinson's disease.

During the last decade, several studies have shown the involvement of a T-cell response specific to pathogenic forms of $\alpha$ Syn in Parkinson's disease patients and in animal models of this disorder [7]. Importantly, the functional phenotype of microglial cells strongly depends on the particular subsets of T-cells that infiltrate the brain. Thus, whereas the pro-inflammatory T-cells subsets T-helper (Th)1 and Th17 promote the acquisition of the M1 phenotype by the microglia, the regulatory T-cells (Treg) that exert an anti-inflammatory activity promote the M2 phenotype in the microglia [3]. Thereby, the T-cell response plays a key role determining the evolution of the neurodegenerative process involved in Parkinson's disease.

T-cell activation requires the presentation of antigenic peptides on the major histocompatibility complexes (MHC) by antigen-presenting cells. In this regard, whereas class I MHC present peptides recognized by $\mathrm{CD}^{+}{ }^{+} \mathrm{T}$-cells, class II MHC present antigenic peptides recognized by CD4+ ${ }^{+}$T-cells [8]. Class I and class II MHC are encoded by a number of highly polymorphic genes called histocompatibility leukocyte antigens (HLA). Since MHC encoded by different HLA alleles display different preference of peptide-binding and different affinities, the specific HLA alleles able to present $\alpha$ Syn-derived antigens constitutes a key genetic factor to be considered in the risk of Parkinson's disease [9].

This review aims to integrate, summarize and analyse the current evidence involving not only CD4 ${ }^{+}$ T-cells, but also CD8 ${ }^{+} \mathrm{T}$-cells that play an important role in the autoimmune response involved in Parkinson's disease. Moreover, this work also aims to summarize the specific T-cell epitopes derived from the pathogenic forms of $\alpha$ Syn recognized by the autoreactive $\mathrm{CD} 8^{+}$and $\mathrm{CD} 4^{+} \mathrm{T}$-cells and their HLA alleles restriction. Finally, this review aims to summarize and discuss a number of experimental immunotherapies involving the potentiation of $\alpha$ Syn-specific Treg response or dampening the $\alpha$ Syn-specific inflammatory T-cell response in preclinical models.

\section{Role of T-cells in the development of neuroinflammation and neurodegeneration involved in Parkinson's disease}

Many studies have provided evidence that T-cells infiltrate the brain in animal models of Parkinson's disease, including the 1-methyl-4-phenyl-1,2,3,6-tetrahydropyridine (MPTP) model in mouse [10-12], 6-hydroxydopamine (6-OHDA) induced neurodegeneration in mice [13] and rats [14], transgenic mice 
overexpressing the human $\alpha$ Syn (h $\alpha$ Syn, Thy1-SNCA) [15, 16], the stereotaxic delivery of adeno-associated viral vectors (AAV) encoding for the wild-type hoSyn in mice [17, 18] and rats [19-21], and the stereotaxic delivery of AAV encoding for the A53T mutant form of h $\alpha$ Syn in rats [22]. Moreover, several studies have shown that T-cell deficient mice $[10,12,23]$ and rats [21] are significantly protected of neurodegeneration development in animal models of Parkinson's disease, thereby indicating that T-cell response seems to play a fundamental role in this disorder. Importantly, a recent longitudinal case study in Parkinson's disease patients revealed an elevated T-cell response specific to $\alpha$ Syn-derived antigens, which may be detected prior motor impairment. This T-cell response was highest early after motor diagnosis and then declined progressively [24]. Thus, these findings suggest an important role of T-cell-driven inflammation in early stages of Parkinson disease development in human individuals.

Some studies carried out in animal models of Parkinson's disease have suggested that despite both $\mathrm{CD}^{+}$and $\mathrm{CD}^{+}{ }^{+} \mathrm{T}$-cells infiltrate the central nervous system (CNS), only $\mathrm{CD}^{+} \mathrm{T}$-cells are required for neurodegeneration, whilst $\mathrm{CD}^{+} \mathrm{T}$-cells are of lesser relevance for the development of this disease. In this regard, Brochard and colleagues [23] observed that $\mathrm{Cd} 4 \%$ mice but not $\mathrm{Cd} 8 \%$ mice were protected from MPTP-induced degeneration of dopaminergic neurons of the substantia nigra (SN). In addition, Williams and colleagues [17] recently observed that neurodegeneration of dopaminergic neurons of the SN induced in mice by the stereotaxic deliver of AAV-h $\alpha$ Syn is associated with increased expression of class II MHC on myeloid cells in the CNS and a sharp infiltration of interferon-gamma (IFN- $\gamma$ ) producing CD4+ $4^{+}$-cells and CD8 ${ }^{+}$T-cells into the SN. Nevertheless, only T-cell receptor (TCR) $\beta$ or CD4 deficiency, but not CD8 deficiency, attenuated neuroinflammation and neurodegeneration in this mouse model [17].

Although the studies above indicated suggest that CD8 ${ }^{+} \mathrm{T}$-cells are not fundamental for neurodegeneration in some mouse models of Parkinson's disease, increasing evidence obtained from animal models and humans points toward an important role of $\mathrm{CD}^{+} \mathrm{T}$-cell response in the pathogenesis of this disorder. For instance, the treatment of SH-SY5Y neuroblastoma with 1-methyl-4-phenylpyridinium (MPP ${ }^{+}$, the toxic form of MPTP which inhibits mitochondrial respiration promoting the generation of ROS, induced increased class I MHC expression [25], thus suggesting that oxidative stress favours the expression of class I MHC in neurons. Accordingly, the MPTP treatment of mice induced increased class I MHC expression on dopaminergic neurons of the SN, which correlated with $\mathrm{CD}^{+}{ }^{+} \mathrm{T}-$ cell infiltration into the brain. Moreover, the knockdown of class I MHC induced by the stereotaxic delivery of AAV resulted in decreased extent of CD8 ${ }^{+}$T-cells infiltration and presented a trend in the reduction of neurodegeneration of dopaminergic neurons of the SN [25]. Furthermore, mechanistic analyses indicated that PTEN-induced kinase 1 (PINK1) was repressing the class I MHC expression in neurons [25]. PINK1 is involved in the clearance of damaged mitochondria by mitophagy and PINK1 mutations have been associated with Parkinson's disease [26].

Interestingly, Matheoud and colleagues [26] provided evidence that PINK1 inhibits the presentation of mitochondria-derived auto-antigens in class I MHC upon stimulation by lipopolysaccharide (LPS) or gram-negative bacteria in vivo. Thus, the absence of PINK1 triggers the presentation of mitochondrial autoantigens in class I MHC and the consequent activation of autoreactive CD8 ${ }^{+}$T-cells. Accordingly, the infection of Pink1-deficient mice with Citrobacter rodentium, a mouse intestinal gram-negative pathogen that is used as a model of human enteropathogenic Escherichia coli infection, induces a CD8 ${ }^{+}$T-cell-mediated autoimmune response directed to mitochondrial antigens [26]. This autoimmune response affected specially to dopaminergic neurons of the SN, which display high mitochondrial activity, thereby promoting the loss of dopaminergic terminals in the striatum and motor impairment.

According to the involvement of $\mathrm{CD}^{+} \mathrm{T}$-cells in the loss of dopaminergic neurons in some animal models of Parkinson's disease, it has been described that catecholaminergic neurons of the SN and Locus Coeruleus in humans express MHC class I, rendering them susceptible to cytotoxic attack by antigen-specific CD8 ${ }^{+}$ T-cells [27]. Accordingly, a recent study analysed the extent of T-cell infiltration into the SN and the association with neuronal death and synucleinopathy at different disease stages in Parkinson's disease patients. The results showed a robust $\mathrm{CD} 8^{+} \mathrm{T}$-cell infiltration into the $\mathrm{SN}$ at early stages of the disease, when the neuronal death was still absent and the $\alpha$ Syn aggregation was confined to the olfactory bulb but absent in the SN [28]. 
In later stages of the pathology, these authors found a lower CD8 ${ }^{+}$T-cell infiltration associated to neuronal loss and accumulation of $\alpha$ Syn aggregates in the SN [28]. Interestingly, most CD8 ${ }^{+}$T-cells infiltrating the SN had a phenotypic profile of tissue resident memory T-cells. Thus, this study suggests that a cytotoxic CD8 ${ }^{+}$ T-cell response may be involved in the initiation and propagation of neuronal death and synucleinopathy in Parkinson's disease [28]. Altogether, the above evidence suggests that despite some animal models show the $\mathrm{CD}^{+} \mathrm{T}$-cell response is not necessary for the neurodegenerative process, recent studies in animals and humans indicate that not only $\mathrm{CD}^{+}$but also $\mathrm{CD} 8^{+} \mathrm{T}$-cells play important roles in the development of neurodegeneration in Parkinson's disease.

Interestingly, despite most studies indicate that T-cell mediated autoimmune response to $\alpha$ Syn plays a detrimental role in the physiopathology of Parkinson's disease, there is also evidence indicating that T-cell response might be beneficial under some circumstances. For instance, it has recently been shown that the transfer of T-cells into immunodeficient mice (NOD SCID gamma-chain deficient, NSG) reduces the deposits of phospho-S129- $\alpha$ Syn, one of the pathogenic forms of $\alpha$ Syn, in the striatum and frontal cortex in a model of Parkinson's disease induced by the injection of h $\alpha$ Syn preformed fibrils (PFF) into the striatum [29].

In addition, it has been shown that lymphocyte deficiency exacerbates the motor impairment and loss of dopaminergic neurons of the nigrostriatal pathway in mice lesioned with unilateral stereotaxic injection of 6-OHDA in the medial forebrain bundle [30]. Moreover, other studies have shown that the immunization of rats or mice with a low dose of $\alpha$ Syn in a mix with complete Freund's adjuvant (CFA), but not with CFA alone, resulted in the generation of $\alpha$ Syn-specific Treg cells and the consequent attenuation of neurodegeneration in models of Parkinson's disease induced by the stereotaxic injection of AAV-h $\alpha$ Syn in the SN [19, 31]. Although therapies involving the usage of CFA are not allowed for the treatment of humans due to its high toxicity [32], these studies encourage the design of immunotherapies for Parkinson's disease based in the generation of Treg responses specific to pathogenic forms of the $\alpha$ Syn. Current evidence indicating how T-cells participate in the development of Parkinson's disease is integrated in the Figure 1.

\section{T-cells antigens involved in Parkinson's disease}

Similar to other autoimmune diseases, the genetic factors associated with Parkinson's disease risk include the polymorphism of MHC molecules. In this regard, different MHC alleles involve distinct preferences of peptide-binding and affinities, thereby implicating the activation of different T-cell clones [33]. According to the involvement of both $\mathrm{CD}^{+}$and $\mathrm{CD}^{+} \mathrm{T}$-cell responses, this disorder has been associated with some particular alleles of class II and class I MHC genes respectively, including first the DRB1*15:01 and DRB5*01:01 alleles [34] and later the DQB1*03:04 and A*11:01 alleles [9].

Importantly, the specific MHC alleles associated to Parkinson's disease are required to the proper presentation of antigens derived of the $\alpha$ Syn. Evidence obtained from human and animal models has shown the presence of $\alpha$ Syn containing 3-nitrotyrosines ( $\alpha$ Syn) in the SN of individuals with Parkinson's disease [10, $35,36]$, a modified form of $\alpha$ Syn that is found mainly in the $\alpha$ Syn inclusions contained in Lewy bodies. It is noteworthy that the nitration of $\alpha$ Syn is a consequence of the oxidative stress induced by ROS and RNS, and that this kind of posttranslational modification involves the generation of a neo-antigens [37].

In this regard, it has been described a C-terminus region of $\alpha$ Syn including the residues 101-140 $\left(\alpha \mathrm{Syn}_{101-140}\right)$ involving four 3-nitrotyrosines which represents antigenic T-cell reactivity in the mouse model of Parkinson's disease induced by MPTP [10]. Interestingly, the epitopes derived from the nitrotyrosinecontaining mouse $\mathrm{N} \alpha \mathrm{Syn}_{101-140}$ were properly presented on the murine class II MHC molecules encoded by alleles IA ${ }^{\mathrm{k}}$ and $\mathrm{IA}^{\mathrm{b}}$. Accordingly, CD $4^{+} \mathrm{T}$-cell responses specific to $\mathrm{N} \alpha \mathrm{Syn}_{101-140}$ were evoked in mice bearing the $\mathrm{H} 2^{\mathrm{K}}$ (B10.BR strain) and $\mathrm{H} 2^{\mathrm{b}}$ (C57BL/6) haplotypes when treated with MPTP [10].

With regard to the presence of T-cell epitopes in unmodified $\alpha$ Syn, Davtyan and colleagues [38] evaluated the activation of T-cells in C57BL/ 6 mice (haplotype $\mathrm{H} 2^{\mathrm{b}}$ ) immunized with a battery of overlapping peptides obtained from the aminoacidic sequence of unmodified $\alpha$ Syn, and they found only the $\alpha \mathrm{Syn}_{76-95}$ and the $\alpha \mathrm{Syn}_{106-125}$ peptides were able to induce IFN- $\gamma$ production by T-cells. Thus, taken together these results indicate that, compared with unmodified $\alpha$ Syn, pathogenic forms of $\alpha$ Syn contains different T-cell epitopes, 
an important point to be considered at the moment of developing T-cell mediated immunotherapies geared to target selectively only pathogenic forms of $\alpha$ Syn, but not healthy $\alpha$ Syn.

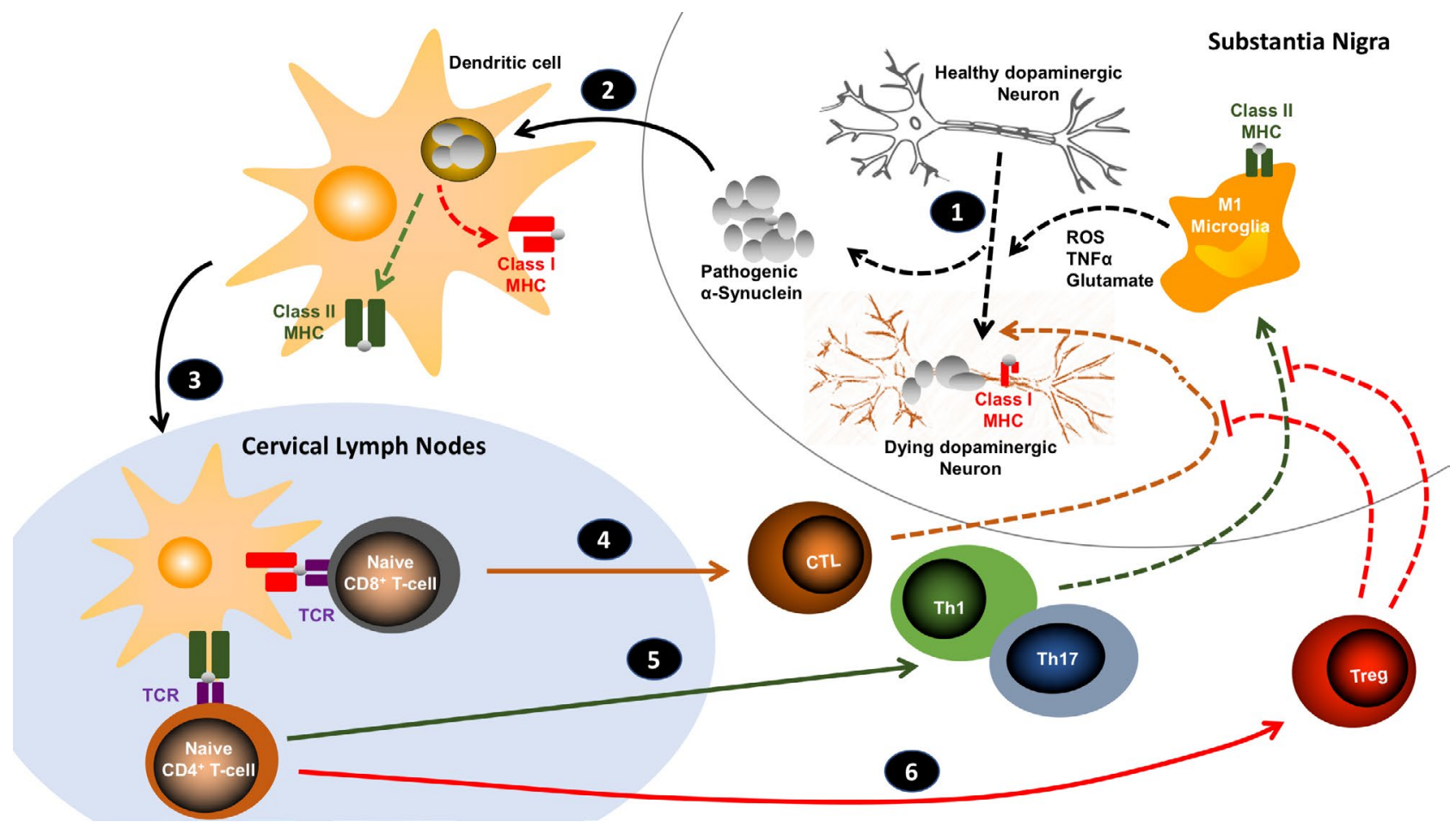

Figure 1. Working model for the role of the T-cell response in the development of Parkinson's disease. 1. An initial generation of ROS (i.e. by mitochondrial dysfunction) promotes the oxidation and aggregation of aSyn, inducing the generation of pathogenic forms of aSyn (oligomers, fibrils, Lewy bodies). Pathogenic aSyn also stimulate TLRs on microglia, triggering further ROS production and secretion of pro-inflammatory cytokines and glutamate, which favour the expression of class I MHC on neurons and eventually neuronal death. 2. Pathogenic aSyn is captured and processed by dendritic cells and subsequently presented on class I and class II MHC molecules. 3. Once dendritic cells arrive to cervical lymph nodes, they present aSyn-derived antigens to naive T-cells. 4. When naive $\mathrm{CD} 8^{+} \mathrm{T}$-cells recognize their specific antigens (through the T-cell receptor; TCR), they become activated and differentiate into cytotoxic T lymphocytes (CTL), which subsequently infiltrate the brain and directly kill neurons presenting their specific antigens on surface class I MHC. 5. Naive CD4+ T-cells specific for the antigens presented by immunogenic dendritic cells become activated and acquire inflammatory phenotypes (i.e. Th1 and Th17), which then infiltrate the brain where are restimulated by microglial cells presenting their specific antigens on class II MHC. Upon this restimulation, cytokines produced by $\mathrm{CD}^{+}{ }^{+}$T-cells act on microglial cells potentiating their M1 phenotype and favouring further production of ROS, glutamate and TNFa, inducing neuronal death. 6 . The manipulation of dendritic cells (with tolerogenic properties) might favour the differentiation of naive CD4 ${ }^{+}$T-cells into Treg. These lymphocytes subsequently attenuate the effects exerted by CTLs, Th1 and Th17, dampening the neuroinflammation and stopping neurodegeneration. Solid arrows implicate migration; lined arrows involve processes

The T-cell epitopes derived from $\alpha$ Syn have also been studied in humans. A systematic study analysed the T-cell epitopes involved in Parkinson's disease patients using a battery of overlapping peptides derived from the hoSyn. The results revealed two antigenic regions of the human hoSyn involved in the T-cell response in Parkinson's disease patients, a N-terminus antigenic region involving $\mathrm{hSyn}_{31-46}$ and a C-terminus antigenic region involving the $h \alpha \operatorname{Syn}_{116-140}[9]$.

The N-terminus antigenic region was presented with high affinity by the class II HLA alleles DRB1*15:01, DRB5*01:01 and DQB1*03:04 as well as by the class I HLA allele $A^{*} 11: 01$. Interestingly, despite the N-terminus antigenic region of the hoSyn includes the Y39 which may be phosphorylated in Parkinson's disease, the phosphorylation of this residue was not required for antigenic T-cell response [9].

In contrast, the C-terminus antigenic region of the haSyn associated to T-cell response in Parkinson's disease was not strongly restricted to the HLA alleles described above, and the phosphorylation at the S129 was required for antigenic T-cell response [9]. Of note, the S129 phosphorylation constitutes a pathogenic post-translational modification of $\alpha$ Syn that has been found in Lewy bodies [39]. According to the poor HLA restriction of the C-terminus antigenic region of the h $\alpha$ Syn, a recent study performed with six Parkinson's disease patients revealed that the TCR repertoire of $\alpha$ Syn-specific T-cells was as diverse as the TCR repertoire of T-cells specific for pertussis, a representative foreign antigen that most individuals have been exposed 
to [40]. Altogether these results provide evidence that pathogenic forms of $\alpha$ Syn contain epitopes recognized by autoreactive T-cells, some of them strongly restricted by HLA alleles and others just poorly dependent of HLA alleles (Figure 2).

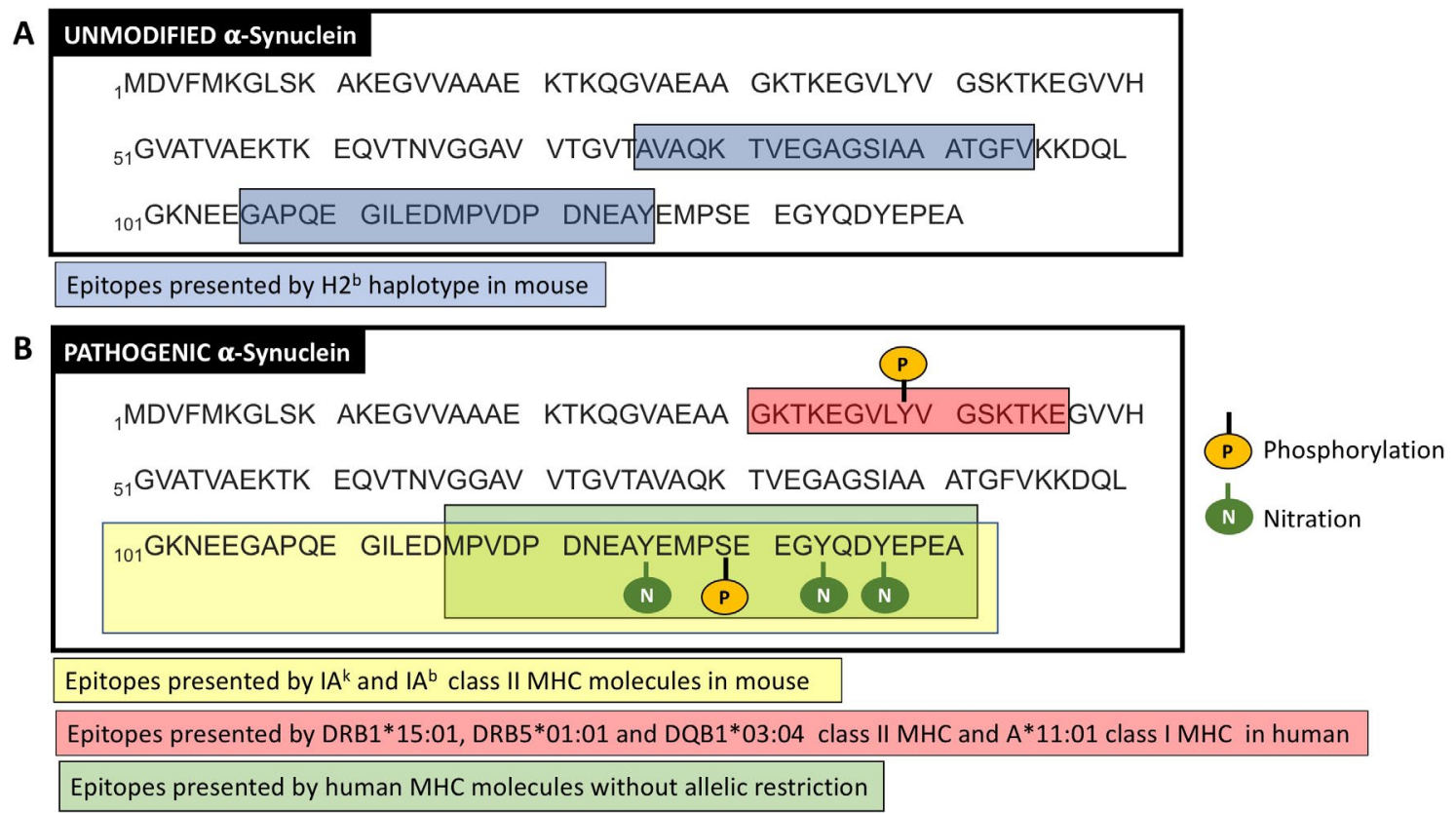

Figure 2. T-cell epitopes from unmodified and pathogenic aSyn. The amino acidic sequence of unmodified (A) and pathogenic (B) forms of aSyn are shown in one-letter code (obtained from UniProt; access number P37840). In (A), blue boxes show the T-cell epitopes presented by $\mathrm{MHC}$ molecules of the $\mathrm{H} 2^{\mathrm{b}}$ haplotype in mice. In (B), the yellow box shows a 3-nitrotyrosine rich region with T-cell epitopes presented by class II MHC molecules $I \mathrm{~A}^{\mathrm{k}}$ and IA $\mathrm{A}^{\mathrm{b}}$ in mice. The green box shows a region with T-cell epitopes presented by human MHC molecules without a strong allelic restriction, but dependent on the phosphorylation on S129. The red box represents a region containing T-cell epitopes presented by some particular alleles of class I and class II MHC (the phosphorylation of $\mathrm{Y} 39$ is not required for presentation on the MHC alleles indicated). Phosphorylations and nitrations are indicated. For better clarity, only haSyn sequences are shown

Another important aspect of pathogenic forms of $\alpha$ Syn as a source of T-cell antigens in Parkinson's disease lies on the physicochemical nature of $\alpha$ Syn oligomers. Interestingly, even in the absence of sequence similarities, oligomers from different proteins often share some structural features, including hydrophobic surfaces [41-43]. These hydrophobic surfaces present in protein aggregates typically represent major stimulator of innate immune cells [44-46]. In this direction, a recent study evaluated the physicochemical features of oligomers relevant to stimulate human $\mathrm{T}$ lymphocytes using the $\mathrm{N}$-terminal domain of the HypF protein from E. coli as a model of misfolded protein oligomers [47]. Of note, two different oligomeric structures might be induced with this model due to a differential organization in the core region, type $\mathrm{A}$ and type B oligomers. Type A oligomers display higher degree of surface hydrophobicity compared to type B oligomers [48]. Importantly, Leal-Lasarte and colleagues [47] showed that type A oligomers induced greater degree of Treg differentiation in human peripheral blood mononuclear cells (PBMC) and more potent suppressive activity in isolated human Treg compared with the effect of type B oligomers. Nevertheless, type A oligomers also promoted higher degree of Th1 and Th17 differentiation in total PBMC compared to type B oligomers [47]. Thus, it seems the greater the extent of hydrophobic surfaces on the oligomer, the more potent the T-cell response either inflammatory or anti-inflammatory. With this in mind, it would be useful to develop $\alpha$ Syn oligomers with high degree of hydrophobic surfaces in therapies geared to generate Treg responses specific to $\alpha$ Syn-derived antigens as a treatment for Parkinson's disease.

Interestingly, some studies suggest the possibility that autoreactive T-cell responses might be triggered by the herpes simplex virus 1 (HSV1) infection due to molecular mimicry of viral components with $\alpha$ Syn. In this regard, Caggiu and colleagues $[49,50]$ found a positive correlation for the presence of T-cell responses specific for hoSyn and HSV1 in Parkinson's disease patients. This correlation seems to be due to molecular similarities in the T-cell epitopes found in $\mathrm{h} \alpha \mathrm{Syn}\left(\mathrm{h} \alpha \mathrm{Syn}_{100-114}\right)$ and the HSV1 protein UL42 (UL42 ${ }_{22-36}$ ) [50]. 


\section{Current experimental immunotherapies targeting T-cell response in Parkinson's disease}

Since the T-cell response to $\alpha$ Syn-derived antigens has been extensively involved in the development of neuroinflammation and consequent neurodegeneration in Parkinson's disease, many researchers have attempted to attenuate this T-cell response as a therapeutic approach to stop the disease progression. Some studies have sought to decrease the inflammatory response induced by Th1 and Th17 cells, others have attempted to potentiate the immunosuppressive response of Treg, and other researchers have tried to do both.

To inhibit the inflammatory T-cell response involved in Parkinson's disease, a group of studies has tested the therapeutic potential of the well-known immunosuppressive drug FK506 (also called tacrolimus), which has been broadly used to inhibit the graft rejection. Its immunosuppressive effect lies in the binging to the immunophilin FK506-binding protein (FKBP) to form the FK506-FKBP complex, which inhibits calcineurin activity, thus attenuating T-cell activation [51,52]. This immunosuppressive drug has shown therapeutic effects reducing the number of T-cells infiltrated into the $\mathrm{SN}$, and attenuating the motor impairment and the neurodegeneration in a rat model of Parkinson's disease induced by the unilateral stereotaxic delivery of AAV encoding for the A53T h $\alpha$ Syn [22]. FK506 has also shown to protect from the reduction of dopamine contained in the striatum in the mouse model of neurodegeneration induced by MPTP [53].

Another drug used to attenuate the inflammatory T-cell response into the CNS in fingolimod (also called FTY720). This drug is a functional antagonist of the sphingosine-1-phosphate receptor, whose stimulation is required for the egress of T-cells from the secondary lymphoid organs. Consequently, this drug reduces the entrance of T-cells into the CNS [54]. Importantly, fingolimod has shown significant therapeutic effects in multiple sclerosis, an autoimmune disorder that involves a T-cell driven neuroinflammation [54]. Due to the parallelism between multiple sclerosis and Parkinson's disease, several groups have tested the therapeutic potential of fingolimod in animal models of Parkinson's disease. These studies have found significant therapeutic effects of fingolimod attenuating the disease development in animal models of neurodegeneration induced MPTP, 6-OHDA, rotenone or by the stereotaxic delivery of AAV-h $\alpha$ Syn in the SN [17, 55-57].

A group of studies have tested the therapeutic potential of drugs improving the Treg response as a treatment for Parkinson's disease. For instance, a recent study sought to induce the generation of $\alpha$ Syn-specific Treg cells as a treatment of Parkinson's disease using microparticles loaded with hoSyn and rapamycin in a transgenic mouse model that involves the overexpression of h $\alpha$ Syn. The results of this study show that this therapeutic approach indeed increased the extent of Treg infiltrating the CNS and reduced the deposits of pathogenic forms of $\alpha$ Syn and limited the development of neuroinflammation and neurodegeneration [58].

Another Treg-based experimental therapy for Parkinson's disease has used a nicotinic agonist of the cholinergic receptor $\alpha 7$ ( $\alpha 7 \mathrm{nAChR}$ ), PNU-282987, which has been shown to increase Treg response [59]. This study provided data indicating that the intraperitoneal administration of PNU-282987 increased the extent of Treg infiltration into the SN of rats treated with the stereotaxic delivery of 6-OHDA into the medial forebrain bundle. This increased Treg infiltration was associated with a significant reduction in the motor impairment, attenuated loss of dopaminergic neurons in the SN, and decreased astrogliosis [59].

An interesting example of immunotherapy based in the potentiation of Treg response has used the vasoactive intestinal peptide (VIP), which has been described to increase the Treg number and their activity [60,61]. According to its immunosuppressive potential, the adoptive transfer of VIP-generated Treg in mice treated with MPTP exerted a strong therapeutic effect attenuating microglial activation and neurodegeneration of the nigrostriatal pathway [11]. In addition to its effect on Treg cells, VIP might also induce the acquisition of tolerogenic features in dendritic cells (DCs) [62]. In this regard, VIP-generated tolerogenic DCs not only favour the expansion of Treg, but also induce the differentiation of naive CD4+ T-cells into $\operatorname{Tr} 1$ cells, another subset of T-cells with immunosuppressive activity [63]. Due to the multi-target nature of VIP inducing immunosuppression, Gendelman's team generated a synthetic version of VIP (LBT-3627) with enhanced resistance to proteases and thereby increased half-life. Accordingly, the treatment of MPTP-mice or rats overexpressing h $\alpha$ Syn with LBT-3627 has shown promising results, attenuating microglial activation and reducing the extent of neurodegeneration $[64,65]$. 
Another immunotherapy proposed for the treatment of Parkinson's disease is based in the anti-inflammatory effects of granulocyte-monocyte colony-stimulating factor (GM-CSF) on DCs, which induces the acquisition of tolerogenic properties in these cells, thereby favouring the generation of Treg cells [66-68]. Accordingly, Lipid nanoparticle containing mRNA encoding GM-CSF were administered intramuscular in MPTP-mice or rats overexpressing $\alpha$ Syn [69]. The treatment induced a rise in plasma GM-CSF and increased frequency of peripheral Treg cells. Concomitantly, the treatment reduced neuroinflammation and neurodegeneration of dopaminergic neurons in mouse and rat models of Parkinson's disease [69]. Due to the successful results in preclinical models, the therapeutic potential of recombinant human GM-CSF (sargramostim) for the treatment of Parkinson's disease is currently under study in a clinical trial (NCT03790670).

Finally, a group of studies have sought both increasing Treg responses and attenuating inflammatory T-cell responses at the same time to promote a therapeutic effect in animal models of Parkinson's disease. In this regard, an interesting molecular target to dampen T-cell mediated inflammation in Parkinson's disease is the dopamine receptor D3 (DRD3) [70]. DRD3-signalling in T-cells has been shown to induce Th1 differentiation and to promote Th17 expansion [71], thereby potentiating the function of two subsets of inflammatory T-cells involved in Parkinson's disease [37]. In addition, DRD3-signalling limits the suppressive activity of Treg cells [72], thereby contributing to promote T-cell mediated inflammation. Moreover, DRD3 expression is altered in $\mathrm{CD}^{+}$T-cells obtained from Parkinson's disease patients [73], suggesting the involvement of this receptor in T-cell mediated neuroinflammation in human individuals. DRD3 is selectively stimulated by low dopamine levels found in the nigrostriatal pathway in Parkinson's disease [23]. Accordingly, the genetic deficiency of $\operatorname{Drd} 3$ in $\mathrm{CD} 4^{+}$T-cells results in a strong attenuation of neuroinflammation and neurodegeneration in a mouse model of Parkinson's disease induced by MPTP [12]. Interestingly, DRD3-signalling in astrocytes also contribute to promote neuroinflammation [74]. According to the pro-inflammatory role of DRD3 in T-cells and astrocytes, the systemic administration of a selective DRD3-antagonist, PG01037, has shown to inhibit the motor impairment and to reduce the extent of neurodegeneration in mouse models of Parkinson's disease induced by MPTP and 6-OHDA [75].

Another example of immunotherapeutic approach geared to affect both Treg and inflammatory T-cells to attenuate neuroinflammation in Parkinson's disease involved the prophylactic vaccination with $\alpha$ Syn in combination with the chaperone Grp94 and CFA in the MPTP mouse model [76]. Using direct immunization of MPTP-treated mice or the adoptive transfer of splenocytes isolated from vaccinated animals into MPTP-treated mice, the authors observed a significant reduction of microglial activation in the SN and the striatum. Mechanistical analyses indicated that this formulation induced an $\alpha$ Syn-specific adaptive immune response involving Th1 and Treg cells and a humoral response predominantly mediated by IgG1 anti- $\alpha$ Syn antibodies [76]. The different experimental immunotherapies based in the attenuation of T-cell driven neuroinflammation as treatment for Parkinson's disease are summarized in the Table 1.

Table 1. Experimental T-cell-based immunotherapies tested in pre-clinical models of Parkinson's disease

\begin{tabular}{|c|c|c|c|c|}
\hline Treatment & Effect on T-cells & Effect on Parkinson's disease & Model & Reference \\
\hline FK506 & Inhibits T-cell activation & $\begin{array}{l}\text { Attenuates motor impairment and } \\
\text { neurodegeneration }\end{array}$ & $\begin{array}{l}\text { AAV-A53T-haSyn } \\
\text { in rat }\end{array}$ & [22] \\
\hline FTY720 & Arrest T-cells in lymph nodes & Attenuates neuroinflammation & AAV-haSyn in mouse & [17] \\
\hline FTY720 & Arrest T-cells in lymph nodes & $\begin{array}{l}\text { Attenuates motor impairment, } \\
\text { neuroinflammation and neurodegeneration }\end{array}$ & $6-\mathrm{OHDA}$ in mouse & [55] \\
\hline FTY720 & Arrest T-cells in lymph nodes & $\begin{array}{l}\text { Attenuates motor impairment and } \\
\text { neurodegeneration }\end{array}$ & 6-OHDA in mouse & [56] \\
\hline FTY720 & Arrest T-cells in lymph nodes & $\begin{array}{l}\text { Attenuates motor impairment and } \\
\text { neurodegeneration }\end{array}$ & Rotenone in mouse & [56] \\
\hline FTY720 & Arrest T-cells in lymph nodes & $\begin{array}{l}\text { Attenuates motor impairment and } \\
\text { neurodegeneration }\end{array}$ & MPTP in mouse & {$[57]$} \\
\hline $\begin{array}{l}\text { Rapamicyn + } \\
\text { aSyn }\end{array}$ & Increases Treg differentiation & $\begin{array}{l}\text { Attenuates neuroinflammation, } \\
\text { neurodegeneration and synuclein } \\
\text { pathology }\end{array}$ & $\begin{array}{l}\text { Transgenic mice } \\
\text { overexpressing } \\
\text { haSyn }\end{array}$ & [58] \\
\hline
\end{tabular}


Table 1. Experimental T-cell-based immunotherapies tested in pre-clinical models of Parkinson's disease (continued)

\begin{tabular}{|c|c|c|c|c|}
\hline Treatment & Effect on T-cells & Effect on Parkinson's disease & Model & Reference \\
\hline PNU-282987 & Increases Treg response & $\begin{array}{l}\text { Attenuates motor impairment, } \\
\text { neuroinflammation and neurodegeneration }\end{array}$ & $6-\mathrm{OHDA}$ in rat & [59] \\
\hline VIP & $\begin{array}{l}\text { Increases Treg number and } \\
\text { activity }\end{array}$ & $\begin{array}{l}\text { Attenuates neuroinflammation and } \\
\text { neurodegeneration }\end{array}$ & MPTP in mouse & [11] \\
\hline VIP (LBT-3627) & $\begin{array}{l}\text { Increases Treg number and } \\
\text { activity }\end{array}$ & $\begin{array}{l}\text { Attenuates neuroinflammation and } \\
\text { neurodegeneration }\end{array}$ & AAV-haSyn in rat & [64] \\
\hline VIP (LBT-3627) & $\begin{array}{l}\text { Increases Treg number and } \\
\text { activity }\end{array}$ & $\begin{array}{l}\text { Attenuates neuroinflammation and } \\
\text { neurodegeneration }\end{array}$ & $6-O H D A$ in rat & [64] \\
\hline VIP (LBT-3627) & $\begin{array}{l}\text { Increases Treg number and } \\
\text { activity }\end{array}$ & $\begin{array}{l}\text { Attenuates neuroinflammation and } \\
\text { neurodegeneration }\end{array}$ & MPTP in mouse & [65] \\
\hline GM-CSF & Favours Treg generation & $\begin{array}{l}\text { Attenuates neuroinflammation and } \\
\text { neurodegeneration }\end{array}$ & MPTP in mouse & [69] \\
\hline GM-CSF & Favours Treg generation & $\begin{array}{l}\text { Attenuates neuroinflammation and } \\
\text { neurodegeneration }\end{array}$ & AAV-haSyn in rat & [69] \\
\hline PG01037 & $\begin{array}{l}\text { Inhibits Th1/Th17 and } \\
\text { increases Treg activity }\end{array}$ & $\begin{array}{l}\text { Attenuates motor impairment, } \\
\text { neuroinflammation and neurodegeneration }\end{array}$ & MPTP in mouse & [75] \\
\hline PG01037 & $\begin{array}{l}\text { Inhibits Th1/Th17 and } \\
\text { increases Treg activity }\end{array}$ & Attenuates neurodegeneration & $6-\mathrm{OHDA}$ in mouse & [75] \\
\hline Grp94 + aSyn & $\begin{array}{l}\text { Promotes Treg and Th1 } \\
\text { response }\end{array}$ & Attenuates neuroinflammation & MPTP in mouse & [76] \\
\hline
\end{tabular}

Finally, it is important to mention that most of the current therapeutic approaches attempting to manipulate the T-cells response as a treatment for Parkinson's disease are directed to unmodified $\alpha$ Syn, but not specific to pathogenic forms of $\alpha$ Syn. Thus, most of these therapies would attenuate the T-cell-mediated inflammatory response to unmodified $\alpha$ Syn even in healthy conditions. This fact might be potentially dangerous, as an inflammatory T-cell response specific to unmodified $\alpha$ Syn may be beneficial under some particular circumstances, such as in neuronal cancer (i.e. neuroblastoma). Accordingly, to improve the safety of T-cell-based immunotherapies for Parkinson's disease, it is important to direct the Treg response specifically to pathogenic forms of $\alpha$ Syn, but not to unmodified $\alpha$ Syn.

\section{Conclusions}

Current evidence suggests an important role of T-cell-driven inflammation in early stages of Parkinson disease development in human individuals. In addition, recent studies in animals and human individuals indicate that both $\mathrm{CD} 4^{+}$and $\mathrm{CD} 8^{+} \mathrm{T}$-cells play important roles in the development of neurodegeneration in Parkinson's disease. These studies encourage the design of immunotherapies for Parkinson's disease based in the generation of Treg responses specific to pathogenic forms of the $\alpha$ Syn or other antigens relevant for this disorder (i.e. mitochondrial autoantigens). A number of studies that have analysed the T-cell epitopes from $\alpha$ Syn indicate that, compared with unmodified $\alpha$ Syn, pathogenic forms of $\alpha$ Syn contains different T-cell epitopes, an important point to be considered at the moment of developing T-cell mediated immunotherapies geared to target selectively only pathogenic forms of $\alpha$ Syn, but not healthy $\alpha$ Syn. Interestingly, pathogenic forms of $\alpha$ Syn contain epitopes recognized by autoreactive T-cells, some of them strongly restricted by HLA alleles and others just poorly dependent of HLA alleles. Moreover, some studies suggest the possibility that autoreactive T-cell responses might be triggered by HSV1 infection due to molecular mimicry of viral components with $\alpha$ Syn. Furthermore, a number of researchers have designed experimental immunotherapies directed to attenuate the T-cell driven neuroinflammation associated to Parkinson's disease in preclinical models. Some studies have sought to decrease the inflammatory response induced by Th1 and Th17 cells, others have attempted to potentiate the immunosuppressive response of Treg, and other researchers have tried to do both together. However, most of these experimental immunotherapies are not specific for pathogenic forms of $\alpha$ Syn, or even not specific for unmodified $\alpha$ Syn. Further efforts should be done to design T-cell based immunosuppressive immunotherapies specific only for pathogenic forms of $\alpha$ Syn and with no effect on healthy unmodified $\alpha$ Syn. 


\section{Abbreviations}

$\alpha$ Syn: alpha-synuclein

AAV: adeno-associated viral vectors

CFA: complete Freund's adjuvant

CNS: central nervous system

DCs: dendritic cells

DRD3: dopamine receptor D3

GM-CSF: granulocyte-monocyte colony-stimulating factor

h $\alpha$ Syn: human $\alpha$ Syn

HLA: histocompatibility leukocyte antigens

HSV1: herpes simplex virus 1

MHC: major histocompatibility complex

MPTP: 1-methyl-4-phenyl-1,2,3,6-tetrahydropyridine

N $\alpha$ Syn: $\alpha$ Syn containing 3-nitrotyrosines

NSG: NOD SCID gamma-chain deficient

PINK1: PTEN-induced kinase 1

ROS: reactive oxygen species

SN: substantia nigra

TCR: T-cell receptor

Th: T helper

TNF $\alpha$ : tumour necrosis factor $\alpha$

Treg: regulatory $\mathrm{T}$ cells

VIP: vasoactive intestinal peptide

6-OHDA: 6-hydroxydopamine

\section{Declarations}

\section{Author contributions}

The author contributed solely to the work.

\section{Conflicts of interest}

The author declares that he has no conflicts of interest.

\section{Ethical approval}

Not applicable.

\section{Consent to participate}

Not applicable.

\section{Consent to publication}

Not applicable.

Availability of data and materials

Not applicable.

\section{Funding}

This work was supported by Programa de Apoyo a Centros con Financiamiento Basal [AFB-170004] from "Comisión Nacional de Investigación Científica y Tecnológica de Chile (CONICYT)", by grants 
[FONDECYT-1210013] from "Fondo Nacional de Desarrollo Científico y Tecnológico de Chile", and [MJFF15076] from the Michael J. Fox Foundation for Parkinson's research. The funders had no role in study design, data collection and analysis, decision to publish, or preparation of the manuscript.

\section{Copyright}

(c) The Author(s) 2021.

\section{References}

1. Braak H, Del Tredici K, Rüb U, de Vos RAI, Jansen Steur ENH, Braak E. Staging of brain pathology related to sporadic Parkinson's disease. Neurobiol Aging. 2003;24:197-211.

2. Lim KL, Zhang CW. Molecular events underlying Parkinson's disease - an interwoven tapestry. Front Neurol. 2013;4:33.

3. González H, Pacheco R. T-cell-mediated regulation of neuroinflammation involved in neurodegenerative diseases. J Neuroinflammation. 2014;11:201.

4. Kim C, Ho DH, Suk JE, You S, Michael S, Kang J, et al. Neuron-released oligomeric $\alpha$-synuclein is an endogenous agonist of TLR2 for paracrine activation of microglia. Nat Commun. 2013;4:1562.

5. Noelker C, Morel L, Lescot T, Osterloh A, Alvarez-Fischer D, Breloer M, et al. Toll like receptor 4 mediates cell death in a mouse MPTP model of Parkinson disease. Sci Rep. 2013;3:1393.

6. González H, Elgueta D, Montoya A, Pacheco R. Neuroimmune regulation of microglial activity involved in neuroinflammation and neurodegenerative diseases. J Neuroimmunol. 2014;274:1-13.

7. Campos-Acuña J, Elgueta D, Pacheco R. T-cell-driven inflammation as a mediator of the gut-brain axis involved in Parkinson's disease. Front Immunol. 2019;10:239.

8. Braciale TJ, Morrison LA, Sweetser MT, Sambrook J, Gething MJ, Braciale VL. Antigen presentation pathways to class I and class II MHC-restricted T lymphocytes. Immunol Rev. 1987;98:95-114.

9. Sulzer D, Alcalay RN, Garretti F, Cote L, Kanter E, Agin-Liebes J, et al. T cells from patients with Parkinson's disease recognize $\alpha$-synuclein peptides. Nature. 2017;546:656-61.

10. Benner EJ, Banerjee R, Reynolds AD, Sherman S, Pisarev VM, Tsiperson V, et al. Nitrated $\alpha$-synuclein immunity accelerates degeneration of nigral dopaminergic neurons. PLoS One. 2008;3:e1376.

11. Reynolds AD, Stone DK, Hutter JA, Benner EJ, Mosley RL, Gendelman HE. Regulatory T cells attenuate Th17 cell-mediated nigrostriatal dopaminergic neurodegeneration in a model of Parkinson's disease. J Immunol. 2010;184:2261-71.

12. González H, Contreras F, Prado C, Elgueta D, Franz D, Bernales S, et al. Dopamine receptor D3 expressed on $\mathrm{CD} 4^{+} \mathrm{T}$ cells favors neurodegeneration of dopaminergic neurons during Parkinson's disease. J Immunol. 2013;190:5048-56.

13. Theodore S, Maragos W. 6-hydroxydopamine as a tool to understand adaptive immune system-induced dopamine neurodegeneration in Parkinson's disease. Immunopharmacol Immunotoxicol. 2015; 37:393-9.

14. Ambrosi G, Kustrimovic N, Siani F, Rasini E, Cerri S, Ghezzi C, et al. Complex changes in the innate and adaptive immunity accompany progressive degeneration of the nigrostriatal pathway induced by intrastriatal injection of 6-hydroxydopamine in the rat. Neurotox Res. 2017;32:71-81.

15. Iba M, Kim C, Sallin M, Kwon S, Verma A, Overk C, et al. Neuroinflammation is associated with infiltration of T cells in Lewy body disease and $\alpha$-synuclein transgenic models. J Neuroinflammation. 2020;17:214.

16. Sommer A, Fadler T, Dorfmeister E, Hoffmann AC, Xiang W, Winner B, et al. Infiltrating T lymphocytes reduce myeloid phagocytosis activity in synucleinopathy model. J Neuroinflammation. 2016;13:174.

17. Williams GP, Schonhoff AM, Jurkuvenaite A, Gallups NJ, Standaert DG, Harms AS. CD4 T cells mediate brain inflammation and neurodegeneration in a mouse model of Parkinson disease. Brain. 2021;144:2047-59. 
18. Theodore S, Cao S, McLean PJ, Standaert DG. Targeted overexpression of human $\alpha$-synuclein triggers microglial activation and an adaptive immune response in a mouse model of Parkinson disease. J Neuropathol Exp Neurol. 2008;67:1149-58.

19. Sanchez-Guajardo V, Annibali A, Jensen PH, Romero-Ramos M. $\alpha$-Synuclein vaccination prevents the accumulation of parkinson disease-like pathologic inclusions in striatum in association with regulatory T cell recruitment in a rat model. J Neuropathol Exp Neurol. 2013;72:624-45.

20. Sanchez-Guajardo V, Febbraro F, Kirik D, Romero-Ramos M. Microglia acquire distinct activation profiles depending on the degree of $\alpha$-synuclein neuropathology in a rAAV based model of Parkinson's disease. PLoS One. 2010;5:e8784.

21. Subbarayan MS, Hudson C, Moss LD, Nash KR, Bickford PC. T cell infiltration and upregulation of MHCII in microglia leads to accelerated neuronal loss in an $\alpha$-synuclein rat model of Parkinson's disease. J Neuroinflammation. 2020;17:242.

22. Van der Perren A, Macchi F, Toelen J, Carlon MS, Maris M, de Loor H, et al. FK506 reduces neuroinflammation and dopaminergic neurodegeneration in an $\alpha$-synuclein-based rat model for Parkinson's disease. Neurobiol Aging. 2015;36:1559-68.

23. Brochard V, Combadière B, Prigent A, Laouar Y, Perrin A, Beray-Berthat V, et al. Infiltration of CD4 ${ }^{+}$ lymphocytes into the brain contributes to neurodegeneration in a mouse model of Parkinson disease. J Clin Invest. 2009;119:182-92.

24. Lindestam Arlehamn CS, Dhanwani R, Pham J, Kuan R, Frazier A, Rezende Dutra J, et al. $\alpha$-Synucleinspecific $\mathrm{T}$ cell reactivity is associated with preclinical and early Parkinson's disease. Nat Commun. 2020;11:1875.

25. Wang BY, Ye YY, Qian C, Zhang HB, Mao HX, Yao LP, et al. Stress increases MHC-I expression in dopaminergic neurons and induces autoimmune activation in Parkinson's disease. Neural Regen Res. 2021;16:2521-7.

26. Matheoud D, Cannon T, Voisin A, Penttinen AM, Ramet L, Fahmy AM, et al. Intestinal infection triggers Parkinson's disease-like symptoms in Pink1\% mice. Nature. 2019;571:565-9.

27. Cebrián C, Zucca FA, Mauri P, Steinbeck JA, Studer L, Scherzer CR, et al. MHC-I expression renders catecholaminergic neurons susceptible to T-cell-mediated degeneration. Nat Commun. 2014;5:3633.

28. Galiano-Landeira J, Torra A, Vila M, Bové J. CD8 T cell nigral infiltration precedes synucleinopathy in early stages of Parkinson's disease. Brain. 2020;143:3717-33.

29. George S, Tyson T, Rey NL, Sheridan R, Peelaerts W, Becker K, et al. T cells limit accumulation of aggregate pathology following intrastriatal injection of $\alpha$-synuclein fibrils. J Parkinsons Dis. 2021;11:585-603.

30. Ip CW, Beck SK, Volkmann J. Lymphocytes reduce nigrostriatal deficits in the 6-hydroxydopamine mouse model of Parkinson's disease. J Neural Transm (Vienna). 2015;122:1633-43.

31. Christiansen JR, Olesen MN, Otzen DE, Romero-Ramos M, Sanchez-Guajardo V. $\alpha$-Synuclein vaccination modulates regulatory $\mathrm{T}$ cell activation and microglia in the absence of brain pathology. J Neuroinflammation. 2016;13:74.

32. Sivakumar SM, Safhi MM, Kannadasan M, Sukumaran N. Vaccine adjuvants - current status and prospects on controlled release adjuvancity. Saudi Pharm J. 2011;19:197-206.

33. Kaufman JF, Auffray C, Korman AJ, Shackelford DA, Strominger J. The class II molecules of the human and murine major histocompatibility complex. Cell. 1984;36:1-13.

34. Greenbaum J, Sidney J, Chung J, Brander C, Peters B, Sette A. Functional classification of class II human leukocyte antigen (HLA) molecules reveals seven different supertypes and a surprising degree of repertoire sharing across supertypes. Immunogenetics. 2011;63:325-35.

35. Giasson BI, Duda JE, Murray IV, Chen Q Souza JM, Hurtig HI, et al. Oxidative damage linked to neurodegeneration by selective $\alpha$-synuclein nitration in synucleinopathy lesions. Science. 2000; 290:985-9.

36. Yu Z, Xu X, Xiang Z, Zhou J, Zhang Z, Hu C, et al. Nitrated $\alpha$-synuclein induces the loss of dopaminergic neurons in the substantia nigra of rats. PLoS One. 2010;5:e9956. 
37. González H, Contreras F, Pacheco R. Regulation of the neurodegenerative process associated to Parkinson's disease by CD4+ T-cells. J Neuroimmune Pharmacol. 2015;10:561-75.

38. Davtyan H, Zagorski K, Petrushina I, Kazarian K, Goldberg NRS, Petrosyan J, et al. MultiTEP platformbased DNA vaccines for alpha-synucleinopathies: preclinical evaluation of immunogenicity and therapeutic potency. Neurobiol Aging. 2017;59:156-70.

39. Fujiwara H, Hasegawa M, Dohmae N, Kawashima A, Masliah E, Goldberg MS, et al. $\alpha$-Synuclein is phosphorylated in synucleinopathy lesions. Nat Cell Biol. 2002;4:160-4.

40. Singhania A, Pham J, Dhanwani R, Frazier A, Rezende Dutra J, Marder KS, et al. The TCR repertoire of $\alpha$-synuclein-specific T cells in Parkinson's disease is surprisingly diverse. Sci Rep. 2021;11:302.

41. Bemporad F, Chiti F. Protein misfolded oligomers: experimental approaches, mechanism of formation, and structure-toxicity relationships. Chem Biol. 2012;19:315-27.

42. Knowles TP, Vendruscolo M, Dobson CM. The amyloid state and its association with protein misfolding diseases. Nat Rev Mol Cell Biol. 2014;15:384-96.

43. Hartl FU. Protein misfolding diseases. Annu Rev Biochem. 2017;86:21-6.

44. Seong SY, Matzinger P. Hydrophobicity: an ancient damage-associated molecular pattern that initiates innate immune responses. Nat Rev Immunol. 2004;4:469-78.

45. Moyano DF, Goldsmith M, Solfiell DJ, Landesman-Milo D, Miranda OR, Peer D, et al. Nanoparticle hydrophobicity dictates immune response. J Am Chem Soc. 2012;134:3965-7.

46. Zottig X, Côté-Cyr M, Arpin D, Archambault D, Bourgault S. Protein supramolecular structures: from selfassembly to nanovaccine design. Nanomaterials (Basel). 2020;10:1008.

47. Leal-Lasarte M, Mannini B, Chiti F, Vendruscolo M, Dobson CM, Roodveldt C, et al. Distinct responses of human peripheral blood cells to different misfolded protein oligomers. Immunology. 2021;164:358-71.

48. Campioni S, Mannini B, Zampagni M, Pensalfini A, Parrini C, Evangelisti E, et al. A causative link between the structure of aberrant protein oligomers and their toxicity. Nat Chem Biol. 2010;6:140-7.

49. Caggiu E, Paulus K, Arru G, Piredda R, Sechi GP, Sechi LA. Humoral cross reactivity between $\alpha$-synuclein and herpes simplex-1 epitope in Parkinson's disease, a triggering role in the disease? J Neuroimmunol. 2016;291:110-4.

50. Caggiu E, Paulus K, Galleri G, Arru G, Manetti R, Sechi GP, et al. Homologous HSV1 and alpha-synuclein peptides stimulate a T cell response in Parkinson's disease. J Neuroimmunol. 2017;310:26-31.

51. Liu J, Albers MW, Wandless TJ, Luan S, Alberg DG, Belshaw PJ, et al. Inhibition of $\mathrm{T}$ cell signaling by immunophilin-ligand complexes correlates with loss of calcineurin phosphatase activity. Biochemistry. 1992;31:3896-901.

52. Liu J, Farmer JD Jr, Lane WS, Friedman J, Weissman I, Schreiber SL. Calcineurin is a common target of cyclophilin-cyclosporin A and FKBP-FK506 complexes. Cell. 1991;66:807-15.

53. Kitamura Y, Itano Y, Kubo T, Nomura Y. Suppressive effect of FK-506, a novel immunosuppressant, against MPTP-induced dopamine depletion in the striatum of young C57BL/6 mice. J Neuroimmunol. 1994;50:221-4.

54. Quirant-Sánchez B, Hervás-García JV, Teniente-Serra A, Brieva L, Moral-Torres E, Cano A, et al. Predicting therapeutic response to fingolimod treatment in multiple sclerosis patients. CNS Neurosci Ther. 2018;24:1175-84.

55. Ren M, Han M, Wei X, Guo Y, Shi H, Zhang X, et al. FTY720 attenuates 6-OHDA-associated dopaminergic degeneration in cellular and mouse Parkinsonian models. Neurochem Res. 2017;42:686-96.

56. Zhao P, Yang X, Yang L, Li M, Wood K, Liu Q et al. Neuroprotective effects of fingolimod in mouse models of Parkinson's disease. FASEB J. 2017;31:172-9.

57. Motyl J, Przykaza Ł, Boguszewski PM, Kosson P, Strosznajder JB. Pramipexole and Fingolimod exert neuroprotection in a mouse model of Parkinson's disease by activation of sphingosine kinase 1 and Akt kinase. Neuropharmacology. 2018;135:139-50. 
58. Rockenstein E, Ostroff G, Dikengil F, Rus F, Mante M, Florio J, et al. Combined active humoral and cellular immunization approaches for the treatment of synucleinopathies. J Neurosci. 2018;38:1000-14.

59. Jiang Y, Ma H, Wang X, Wang Z, Yang Y, Li L, et al. Protective effect of the $\alpha 7$ nicotinic receptor agonist PNU282987 on dopaminergic neurons against 6-hydroxydopamine, regulating anti-neuroinflammatory and the immune balance pathways in rat. Front Aging Neurosci. 2021;12:606927.

60. Delgado M, Chorny A, Gonzalez-Rey E, Ganea D. Vasoactive intestinal peptide generates $\mathrm{CD}^{+}{ }^{+} \mathrm{CD} 25^{+}$ regulatory T cells in vivo. J Leukoc Biol. 2005;78:1327-38.

61. Fernandez-Martin A, Gonzalez-Rey E, Chorny A, Ganea D, Delgado M. Vasoactive intestinal peptide induces regulatory T cells during experimental autoimmune encephalomyelitis. Eur J Immunol. 2006;36:318-26.

62. Chorny A, Gonzalez-Rey E, Fernandez-Martin A, Pozo D, Ganea D, Delgado M. Vasoactive intestinal peptide induces regulatory dendritic cells with therapeutic effects on autoimmune disorders. Proc Natl Acad Sci U S A. 2005;102:13562-7.

63. Varela N, Chorny A, Gonzalez-Rey E, Delgado M. Tuning inflammation with anti-inflammatory neuropeptides. Expert Opin Biol Ther. 2007;7:461-78.

64. Mosley RL, Lu Y, Olson KE, Machhi J, Yan W, Namminga KL, et al. A synthetic agonist to vasoactive intestinal peptide receptor-2 induces regulatory T cell neuroprotective activities in models of Parkinson's disease. Front Cell Neurosci. 2019;13:421.

65. Olson KE, Kosloski-Bilek LM, Anderson KM, Diggs BJ, Clark BE, Gledhill JM Jr, et al. Selective VIP receptor agonists facilitate immune transformation for dopaminergic neuroprotection in MPTP-intoxicated mice. J Neurosci. 2015;35:16463-78.

66. Bhattacharya P, Budnick I, Singh M, Thiruppathi M, Alharshawi K, Elshabrawy H, et al. Dual role of GMCSF as a pro-inflammatory and a regulatory cytokine: implications for immune therapy. J Interferon Cytokine Res. 2015;35:585-99.

67. Schutt CR, Gendelman HE, Mosley RL. Tolerogenic bone marrow-derived dendritic cells induce neuroprotective regulatory T cells in a model of Parkinson's disease. Mol Neurodegener. 2018;13:26.

68. Lotfi N, Thome R, Rezaei N, Zhang GX, Rezaei A, Rostami A, et al. Roles of GM-CSF in the pathogenesis of autoimmune diseases: an update. Front Immunol. 2019;10:1265.

69. Olson KE, Namminga KL, Lu Y, Thurston MJ, Schwab AD, de Picciotto S, et al. Granulocyte-macrophage colony-stimulating factor mRNA and Neuroprotective Immunity in Parkinson's disease. Biomaterials. 2021;272:120786.

70. Pacheco R. Targeting dopamine receptor D3 signalling in inflammation. Oncotarget. 2017;8:7224-5.

71. Contreras F, Prado C, González H, Franz D, Osorio-Barrios F, Osorio F, et al. Dopamine receptor D3 signaling on CD4+ T cells favors Th1- and Th17-mediated immunity. J Immunol. 2016;196:4143-9.

72. Ugalde V, Contreras F, Prado C, Chovar O, Espinoza A, Pacheco R. Dopaminergic signalling limits suppressive activity and gut homing of regulatory $\mathrm{T}$ cells upon intestinal inflammation. Mucosal Immunol. 2021;14:652-66.

73. Elgueta D, Contreras F, Prado C, Montoya A, Ugalde V, Chovar O, et al. Dopamine receptor D3 expression is altered in $\mathrm{CD}^{+}$T-cells from Parkinson's disease patients and its pharmacologic inhibition attenuates the motor impairment in a mouse model. Front Immunol. 2019;10:981.

74. Montoya A, Elgueta D, Campos J, Chovar O, Falcón P, Matus S, et al. Dopamine receptor D3 signalling in astrocytes promotes neuroinflammation. J Neuroinflammation. 2019;16:258.

75. Elgueta D, Aymerich MS, Contreras F, Montoya A, Celorrio M, Rojo-Bustamante E, et al. Pharmacologic antagonism of dopamine receptor D3 attenuates neurodegeneration and motor impairment in a mouse model of Parkinson's disease. Neuropharmacology. 2017;113:110-23.

76. Villadiego J, Labrador-Garrido A, Franco JM, Leal-Lasarte M, De Genst EJ, Dobson CM, et al. Immunization with $\alpha$-synuclein/Grp94 reshapes peripheral immunity and suppresses microgliosis in a chronic Parkinsonism model. Glia. 2018;66:191-205. 